\title{
The rhinopharyngeal flap for reconstruction of lower clival and craniovertebral junction defects
}

\author{
Pierre-Olivier Champagne, MD, PhD, ${ }^{1}$ Georgios A. Zenonos, MD, ${ }^{1}$ Eric W. Wang, MD, ${ }^{2}$ \\ Carl H. Snyderman, MD, ${ }^{2}$ and Paul A. Gardner, MD ${ }^{1}$ \\ Departments of ${ }^{1}$ Neurosurgery and ${ }^{2}$ Otolaryngology, University of Pittsburgh Medical Center, Pittsburgh, Pennsylvania
}

\begin{abstract}
OBJECTIVE The endoscopic endonasal approach (EEA) to the lower clivus and craniovertebral junction (CVJ) has been traditionally performed via resection of the nasopharyngeal soft tissues. Alternatively, an inferiorly based rhinopharyngeal (RP) flap (RPF) can be dissected to help reconstruct the postoperative defect and separate it from the oropharynx. To date, there is no evidence regarding the viability and potential clinical impact of the RPF. The aim of this study was to assess RPF viability and its impact on clinical outcome.
\end{abstract}

METHODS A retrospective cohort of 60 patients who underwent EEA to the lower clivus and CVJ was studied. The RPF was used in 30 patients (RPF group), and the nasopharyngeal soft tissues were resected in 30 patients (control group).

RESULTS Chordoma was the most common surgical indication in both groups (47\% in the RPF group vs $63 \%$ in the control group, $p=0.313$ ), followed by odontoid pannus ( $20 \%$ in the RPF group vs $10 \%, p=0.313)$. The two groups did not significantly differ in terms of extent of tumor $(p=0.271)$, intraoperative CSF leak $(p=0.438)$, and skull base reconstruction techniques other than the RPF (nasoseptal flap, $p=0.301$; fascia lata, $p=0.791$; inlay graft, $p=0.793$; and prophylactic lumbar drain, $p=0.781$ ). Postoperative soft-tissue enhancement covering the lower clivus and CVJ observed on MRI was significantly higher in the RPF group (100\% vs $26 \%, p<0.001)$. The RPF group had a significantly lower rate of nasoseptal flap necrosis ( $3 \%$ vs $20 \%, p=0.044)$ and surgical site infection $(3 \%$ vs $27 \%, p=0.026)$ while having similar rates of postoperative CSF leakage (17\% in the RPF group vs $20 \%, p=0.739$ ) and meningitis $(7 \%$ in the RPF group vs $17 \%, p=0.424)$. Oropharyngeal bacterial flora dominated the infections in the control group but not those in the RPF group, suggesting that the RPF acted as a barrier between the nasopharynx and oropharynx.

CONCLUSIONS The RPF provides viable vascularized tissue coverage to the lower clivus and CVJ. Its use was associated with decreased rates of nasoseptal flap necrosis and local infection, likely due to separation from the oropharynx.

https://thejns.org/doi/abs/10.3171/2020.8.JNS202193

KEYWORDS craniovertebral junction; endoscopic endonasal approach; rhinopharynx; skull base reconstruction; skull base surgery; pituitary surgery

$\mathrm{R}$ EFINEMENT of the endoscopic endonasal approach (EEA) has extended access to pathologies of the anterior craniovertebral junction (CVJ) and lower clivus. ${ }^{1}$ In the last decade, there has been a clear shift from the gold standard of transoral approaches, ${ }^{2,3}$ with EEA being increasingly recognized as a potentially less morbid approach providing adequate access to the $\mathrm{CVJ}{ }^{4-6}$

Endonasal access to the CVJ and lower clivus requires transgressing the nasopharyngeal soft tissues. This can be achieved by various methods such as a linear midline incision, ${ }^{7}$ T-shaped midline incision, ${ }^{8,9}$ and excision of tis- sues. ${ }^{10-13}$ Alternatively, an inferiorly based flap of the rhinopharynx (rhinopharyngeal [RP] flap [RPF]) can be used in an attempt to preserve living tissues covering the rhinopharynx for reconstruction. Since its initial use by Kassam et al., ${ }^{1}$ various groups worldwide are currently using this flap to access the anterior CVJ and lower clivus and help with reconstruction. ${ }^{14-17}$ Despite its widespread use, however, no data exist regarding the viability and clinical impact of the RPF. The current study specifically addresses these issues, aiming to assess RPF viability and impact on clinical outcome.

ABBREVIATIONS CVJ = craniovertebral junction; EEA = endoscopic endonasal approach; ICG = indocyanine green; RP = rhinopharyngeal; RPF = RP flap; SNOT-22 = Sino-Nasal Outcome Test.

SUBMITTED June 7, 2020. ACCEPTED August 17, 2020.

INCLUDE WHEN CITING Published online February 12, 2021; DOI: 10.3171/2020.8.JNS202193. 


\section{Methods \\ Study Design}

This study received approval from our institutional internal review board. Due to its retrospective nature and anonymized treatment of information, patient consent was not deemed necessary. This is a retrospective cohort study of patients who underwent an EEA to the CJV and lower clivus in a single institution. The study's cohort was divided into two groups: a group in which the RPF was used for reconstruction (RPF group) and a control group in which the RPF was not used and RP soft tissues were resected instead (control group).

Inclusion criteria for the RPF group were as follows: EEA to any CVJ or lower clival pathology between January 2013 and July 2019 and documented use of the RPF in the operative record. Inclusion criteria for the control group were as follows: EEA to any CVJ or lower clival pathology between January 2013 and July 2019 and documented resection of RP soft tissues in the operative record. Exclusion criteria for both groups were as follows: doubt in the operative record if RPF was used or not, destruction of RP soft tissues by the primary pathology, repeat EEA to the CVJ or lower clivus, and follow-up of less than 6 months. Once the RPF group was defined, selection of the control group started from the most recent case and proceeded in a retrograde fashion to achieve equal group size and similar time periods.

The main outcome measures for RPF viability were flap enhancement on routine postoperative gadolinium-injected MRI and direct visual assessment of the flap on routine postoperative endoscopic examination. A single nonblinded observer evaluated the enhancement of the RP soft tissues on MRI performed within 1 week of the surgery. Tissue enhancement was assessed subjectively as a dichotomic variable (present/absent). The main clinical outcome measures were the occurrence of postoperative CSF leakage, nasoseptal and/or RPF necrosis, postoperative infection, postoperative sinonasal quality of life (via Sino-Nasal Outcome Test [SNOT-22] questionnaire ${ }^{18}$ ), and subjective crusting on routine postoperative endoscopic examination. Other important data regarding patient demographics, skull base defect, and reconstruction were also gathered. For each postoperative infection, every identified germ in culture was classified according to its typical location as part of nasopharyngeal flora, oropharyngeal flora, or both.

\section{Cadaveric Dissections}

To demonstrate the surgical technique of the RPF and to show its vascular pedicle, 2 adult, lightly embalmed cadaveric heads were used for dissection. One head was used to demonstrate the harvest of the RPF, using a $0^{\circ}$ endoscope (Hopkins II, 4-mm diameter $\times 18-\mathrm{cm}$ length, Karl Storz) and standard endoscopic instruments with the head in a supine neutral position. The other head was used to show the RPF vascular pedicle from the ascending pharyngeal artery using both microscopic and endoscopic dissection.

\section{Statistical Analysis}

Statistical analysis was conducted using SPSS software version 24.0 (IBM Corp.). A 2-tailed Student t-test was used for comparison of means of continuous variables. A univariate 2-tailed chi-square test was used for nominal and ordinal variables comparison, and a Fisher's exact test was used when the sample was too small for the chi-square analysis. For all tests, $\mathrm{p}<0.05$ was considered significant.

\section{Surgical Technique of the RPF}

The RPF can be used either when accessing the CVJ alone or with inferior extension of a transclival approach. A posterior septectomy below the sphenoid rostrum is first performed to provide an adequate bilateral working corridor, with drilling of the maxillary crest to the level of the hard palate. Image guidance is used to identify the parapharyngeal segment of the internal carotid arteries bilaterally and evaluate their distance from the flap, as their course can be highly variable, especially in older patients. Doppler ultrasound can also be of use at this step. The flap is then incised following an inverted " $U$ " through the mucosa using needle-tip monopolar electrocautery. The superior portion of the flap usually starts at the level of the sphenoid sinus floor, proceeding laterally to the fossa of Rosenmuller and then inferiorly at the level of the salpingopharyngeal fold, just behind the torus tubarius and salpingopharyngeal muscles bilaterally. Elevation of the RPF is then performed using needle-tip monopolar electrocautery, staying as close as possible to the bone of the clivus, incorporating as much of the basopharyngeal fascia as possible and capitis muscle into the flap. Once the flap is elevated, it is displaced inferiorly, providing a layer separating the oropharynx and rhinopharynx. At the reconstruction phase of the case, the RPF is positioned back in its original location. When a pedicled nasoseptal flap is used in conjunction with the RPF, it is placed so that the periosteum of its inferior edge is in contact with the periosteum of the RPF, avoiding mucosal overlap as much as possible between the two flaps (Fig. 1 and Video 1).

VIDEO 1. Surgical technique of the RPF harvest and positioning at the end of the case. Copyright Pierre-Olivier Champagne.

Published with permission. Click here to view.

\section{Results}

\section{Patient Population}

A total of 68 patients were operated on via EEA involving the inferior clivus and CVJ during the study period. After application of inclusion and exclusion criteria, 3 patients were excluded due to uncertain use of the RPF, 1 patient was excluded from the RPF group due to insufficient follow-up, and 4 patients were excluded from the control group because of destruction of RP tissues by the underlying pathology. Of the remaining 60 patients, 30 were in the RPF group and 30 were in the control group. Of note, all EEAs to the CVJ or lower clivus during the study period were done using either an RPF or soft-tissue resection.

Demographics of the two groups were similar (Table 1). The mean age of the RPF group was 48.8 years old and the mean age of the control group was 47.4 years old; $40 \%$ of patients in the RPF group were male, compared with $33 \%$ in the control group $(\mathrm{p}=0.287)$. There was no statistically significant difference between the two groups in terms of mean preoperative BMI (29.2 in the RPF group 

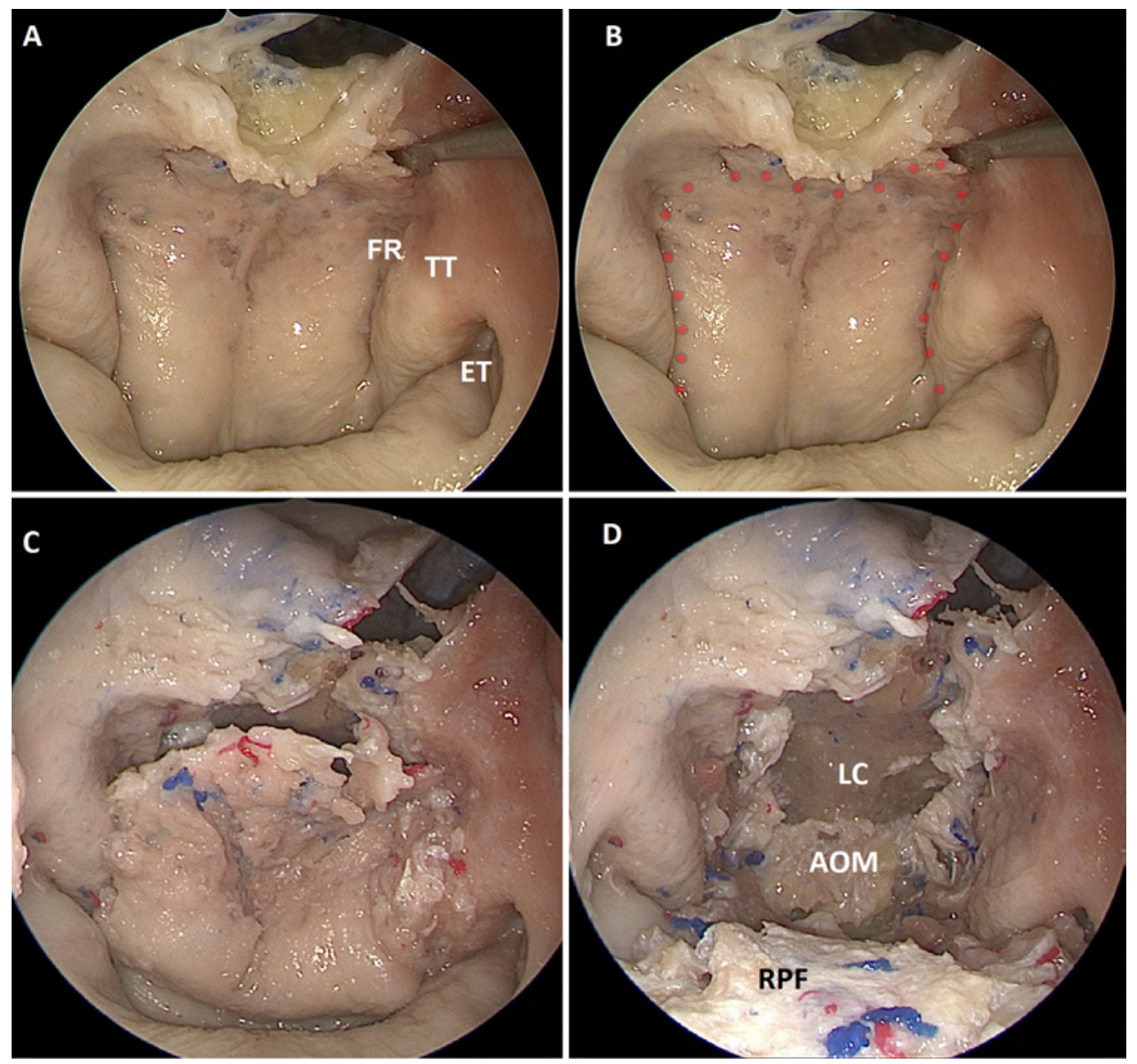

FIG. 1. Cadaveric stepwise dissection of the RPF. A: Anatomical landmarks and harvest site prior to dissection. B: The red dots represent the desired shape of the flap and cuts. Note that the lateral incisions may extend behind the torus tubarius (TT) into the fossa of Rosenmuller (FR) depending on the proximity of the internal carotid arteries. C: The RPF is raised after the horizontal and two vertical cuts have been performed. D: The RPF is displaced inferiorly to expose the lower clivus (LC) and CVJ. AOM = atlantooccipital membrane; ET = eustachian tube. Copyright Pierre-Olivier Champagne. Published with permission. Figure is available in color online only.

vs 28.4 in the control group, $\mathrm{p}=0.681)$, rate of prior endonasal surgery (10\% in the RPF group vs $13 \%, \mathrm{p}=0.688)$, and rate of prior radiation (7\% in the RPF group vs $13 \%$, $\mathrm{p}=0.671$ ). Of note, all cases involving a previous endonasal surgery were recurrent chordomas for which the initial intervention did not involve the lower clivus or CVJ. The main surgical indication in both groups was chordoma (47\% in the RPF group vs $63 \%$ in the control group, $p=$ 0.313 ), followed by odontoid pannus for the RPF group (20\%) and other miscellaneous indications in the control group (17\%). The most common lesion location was the CVJ in both groups $(60 \%$ in the RPF group vs $47 \%$ in the control group, $\mathrm{p}=0.301$ ) followed by panclival location in both groups (23\% in the RPF group vs $20 \%, \mathrm{p}=0.754)$. The primary lesion involved pharyngeal soft tissues in $13 \%$ of patients in the RPF group and $23 \%$ of patients in the control group $(\mathrm{p}=0.317)$. Regarding the timing of intervention in the two groups, $77 \%$ of interventions in the RPF group occurred in or after 2017, and 73\% of interventions in the control group occurred before 2017 ( $p<$ 0.001 ). Figure 2 represents the timing of intervention in each group for each year of the study period.

\section{Surgery and Reconstruction}

The rates of intraoperative CSF leak $(47 \%$ for the RPF group vs $57 \%, \mathrm{p}=0.438)$ and large $\left(\geq 2 \mathrm{~cm}^{2}\right)$ dural defect (33\% for the RPF group vs $30 \%, p=0.781$ ) were not significantly different between the groups (Table 1). Prophylactic use of a lumbar drain to prevent postoperative CSF leakage was also not different between the groups (33\% for the RPF group vs 30\%, $p=0.781$ ). Almost all aspects of the reconstruction technique, including the use of a nasoseptal flap, fat graft, fascia lata graft, inlay collagen matrix, and nasal packing, were not statistically different between the groups. The only different aspect between the groups regarding reconstruction technique was the use of fibrin or other synthetic glue, which was significantly higher in the control group (93\% vs $67 \%, \mathrm{p}=0.001)$. Table 1 summarizes the intraoperative and reconstructive variables in the two groups.

\section{RPF Viability}

Viability of the flap assessed by routine postoperative endoscopic endonasal examinations confirmed good heal- 
TABLE 1. Baseline characteristics

\begin{tabular}{|c|c|c|c|}
\hline Variable & $\begin{array}{l}\text { RPF } \\
\text { Group }\end{array}$ & $\begin{array}{c}\text { Control } \\
\text { Group }\end{array}$ & $\mathrm{p}$ Value \\
\hline No. of patients & 30 & 30 & \\
\hline Mean age, yrs & 48.8 & 47.4 & 0.811 \\
\hline Male sex, $\mathrm{n}(\%)$ & $12(40)$ & $10(33)$ & 0.287 \\
\hline Mean BMI $\left(\mathrm{kg} / \mathrm{m}^{2}\right)$ & 29.2 & 28.4 & 0.681 \\
\hline Prior EEA, n (\%) & $3(10)$ & $4(13)$ & 0.688 \\
\hline Prior radiation, $\mathrm{n}(\%)$ & $2(7)$ & $4(13)$ & 0.671 \\
\hline Diagnosis, n (\%) & & & 0.364 \\
\hline Chordoma & $14(47)$ & $19(63)$ & \\
\hline Odontoid pannus & $6(20)$ & $3(10)$ & \\
\hline Basilar invagination & $5(17)$ & $3(10)$ & \\
\hline Meningioma & $2(7)$ & $0(0)$ & \\
\hline Other & $3(10)$ & $5(17)$ & \\
\hline Lesion extension, n (\%) & & & 0.336 \\
\hline Panclival & $7(23)$ & $6(20)$ & \\
\hline Mid clivus & $5(17)$ & $7(23)$ & \\
\hline Lower clivus & $0(0)$ & $3(10)$ & \\
\hline CVJ & $18(60)$ & $14(47)$ & \\
\hline $\begin{array}{l}\text { Pharyngeal soft-tissue } \\
\text { involvement, } n(\%)\end{array}$ & $4(13)$ & $7(23)$ & 0.317 \\
\hline Intraop CSF leak, n (\%) & $14(47)$ & $17(57)$ & 0.438 \\
\hline$\geq 2-\mathrm{cm}^{2}$ dural defect, $\mathrm{n}(\%)$ & $10(33)$ & $9(30)$ & 0.781 \\
\hline Prophylactic lumbar drain, $n(\%)$ & $10(33)$ & $9(30)$ & 0.781 \\
\hline \multicolumn{4}{|l|}{ Reconstruction } \\
\hline Nasoseptal flap, n (\%) & $14(47)$ & $18(60)$ & 0.301 \\
\hline Fat graft, $\mathrm{n}(\%)$ & $14(47)$ & $18(60)$ & 0.301 \\
\hline Fascia lata graft, n (\%) & $12(40)$ & $11(37)$ & 0.791 \\
\hline Inlay collagen matrix, n (\%) & $13(43)$ & $12(40)$ & 0.793 \\
\hline Glue, $n(\%)$ & $20(67)$ & $28(93)$ & $0.01^{*}$ \\
\hline Nasal packing, $\mathrm{n}(\%)$ & $18(60)$ & $21(70)$ & 0.417 \\
\hline Mean packing duration, days & 8.6 & 7.8 & 0.469 \\
\hline
\end{tabular}

Boldface type indicates statistical significance.

${ }^{*}$ Change in practice.

ing of the flap in all cases, with no case of suspected or confirmed RPF necrosis. Enhancement of the RP tissues on routine postoperative imaging was also significantly higher in the RPF group ( $100 \%$ vs $26 \%$, p < 0.001$)$, confirming that coverage of the rhinopharynx with vascularized tissue is higher when the RPF is used. Of note, immediate or delayed contrast-enhanced postoperative imaging was not available for analysis in 8 patients in the RPF group and 3 patients in the control group. This is mainly due to the fact that the underlying pathologies (e.g., basilar invagination, degenerative atlantoaxial disease) did not warrant contrasted studies. Figure 3 demonstrates a case of RPF enhancement in comparison with a case from the control group without enhancement of the RP tissues.

\section{Clinical Outcomes}

The rate of postoperative CSF leakage was not significantly different between the two groups (17\% for the RPF

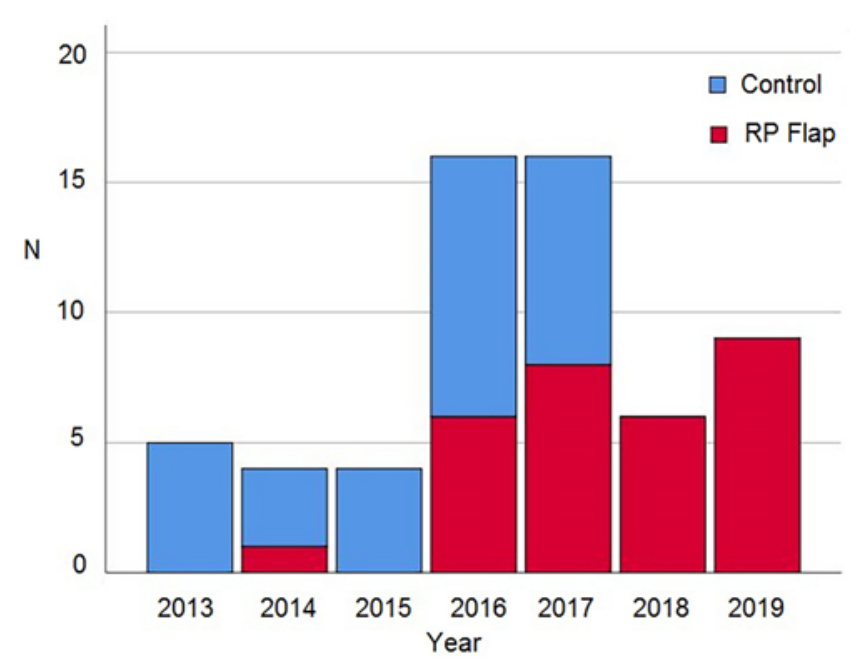

FIG. 2. Timing of surgery of the two study groups. Note the increased adoption of the RPF in recent years. Figure is available in color online only.

group vs $20 \%$ for the control group, $\mathrm{p}=0.739)$. However, the rate of nasoseptal flap necrosis was higher in the control group ( $20 \%$ vs $3 \%, \mathrm{p}=0.044)$, as was the rate of surgical site infection $(27 \%$ vs $3 \%, \mathrm{p}=0.026)$. The rate of meningitis was $7 \%$ in the RPF group and $17 \%$ in the control group $(\mathrm{p}=0.424)$. Table 2 summarizes the main outcomes between the groups. Examining the bacteria involved in all local infections, 14 different strains were isolated from the infections in the control group, and 6 different strains were isolated from the infections in the RPF group (Table 3). Eighty-six percent of the bacteria in the control group were preferentially found as oropharyngeal flora, and the remaining 14\% were found as either normal nasopharyngeal or oropharyngeal flora. ${ }^{18-24}$ For the RPF group, only $17 \%$ of the germs were preferentially found as oropharyngeal flora, and the remaining $67 \%$ were found as either normal oropharyngeal or nasopharyngeal flora. The proportion of bacteria found preferentially in only the oropharynx was statistically significantly higher in the control group ( $86 \%$ vs $17 \%, \mathrm{p}=0.007)$. The presence of crusting noted by an otolaryngologist on routine postoperative endoscopic examination was not statistically significantly different between the groups (27\% for the RPF group vs $50 \%$ in the control group, $\mathrm{p}=0.069)$. The mean postoperative SNOT-22 score was not different between the groups (23.8 for the RPF group vs 24.2 for the control group, $\mathrm{p}=0.959)$.

We performed a subgroup analysis involving only patients with an intraoperative CSF leak $(n=31)$. This analysis showed no major difference from the overall analysis, with no significant difference in baseline characteristics (age, $\mathrm{p}=0.492$; sex, $\mathrm{p}=0.534$; BMI, $\mathrm{p}=0.926$; prior EEA, $\mathrm{p}=0.664$; lesion extension, $\mathrm{p}=0.943$; soft-tissue involvement, $\mathrm{p}=0.597$; and diagnosis, $\mathrm{p}=0.118$ ) between the control group and the RPF group. As with the complete sample, the only statistically significant parameter regarding reconstruction was the use of glue $(100 \%$ in the control group vs $36 \%$ in the RPF group, $\mathrm{p}<0.001)$, with no differ- 

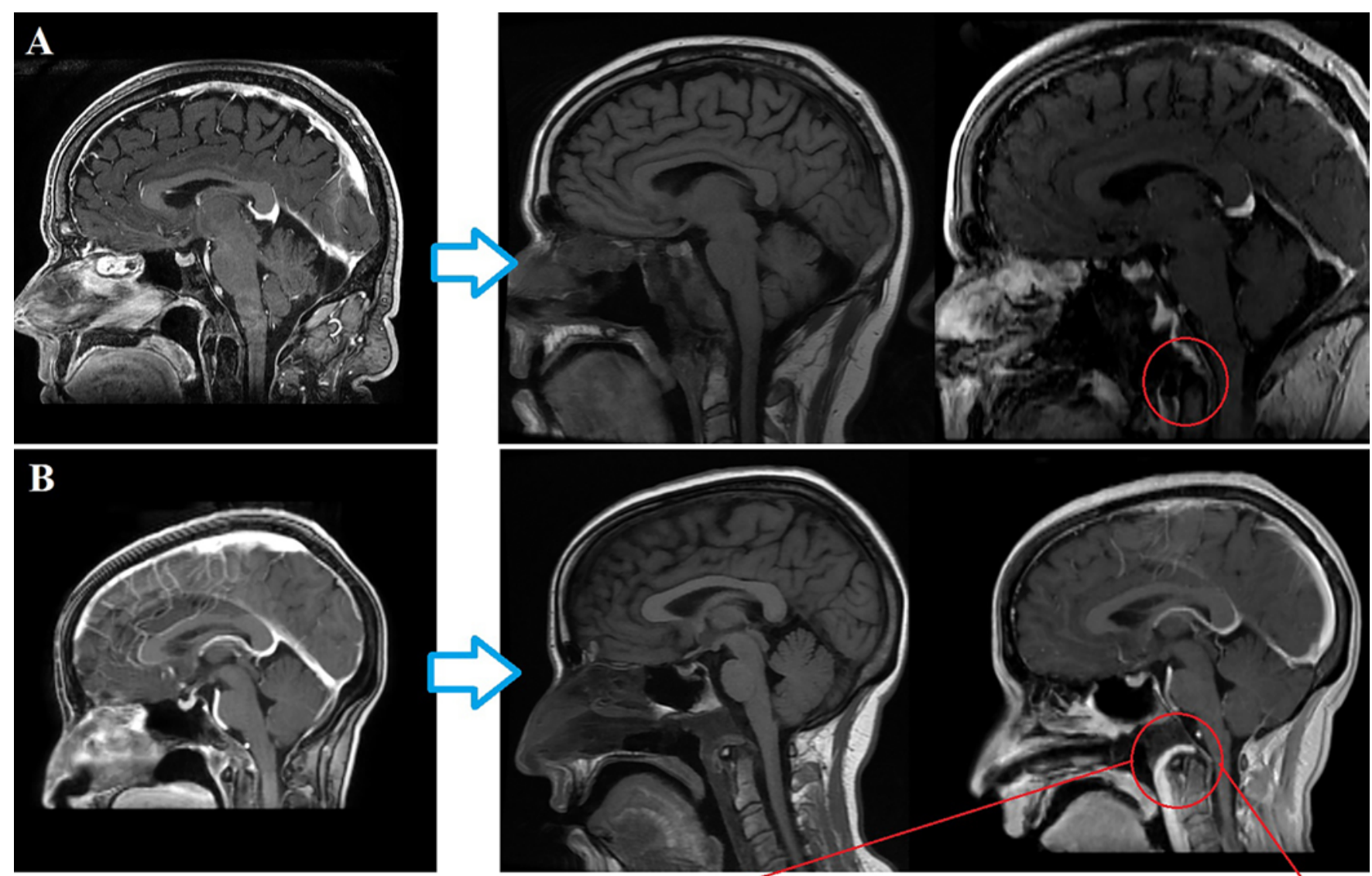
TABLE 2. Primary outcomes

\begin{tabular}{lccr}
\hline \multicolumn{1}{c}{ Variable } & $\begin{array}{c}\text { RPF } \\
\text { Group }\end{array}$ & $\begin{array}{r}\text { Control } \\
\text { Group }\end{array}$ & p Value \\
\hline CSF leak, $\mathrm{n}(\%)$ & $5(17)$ & $6(20)$ & 0.739 \\
\hline Nasoseptal flap necrosis, $\mathrm{n}(\%)$ & $1(3)$ & $6(20)$ & 0.044 \\
\hline RPF necrosis, $\mathrm{n}(\%)$ & $0(0)$ & & \\
\hline Meningitis, $\mathrm{n}(\%)$ & $2(7)$ & $5(17)$ & 0.424 \\
\hline Surgical site infection, $\mathrm{n}(\%)$ & $1(3)$ & $8(27)$ & $\mathbf{0 . 0 2 6}$ \\
\hline Crusting, $\mathrm{n}(\%)$ & $8(27)$ & $15(50)$ & 0.069 \\
\hline RP tissue enhancement, $\mathrm{n}(\%)$ & $21(100)$ & $7(26)$ & $<0.001$ \\
\hline Mean SNOT-22 score & 23.8 & 24.2 & 0.959 \\
\hline
\end{tabular}

Boldface type indicates statistical significance.

did not reach statistical significance (flap necrosis: $35.3 \%$ in the control group vs $7.1 \%, \mathrm{p}=0.094$; surgical site infection: $35.3 \%$ in the control group vs $7.1 \%, \mathrm{p}=0.094$ ).

\section{Discussion}

Skull base reconstruction remains one of the main challenges in endoscopic endonasal skull base surgery. The use of pedicled flaps such as the nasoseptal flap changed the practice of complex endoscopic endonasal reconstruction by significantly decreasing CSF leak rates. ${ }^{25}$ Other potential advantages of pedicled flaps include improved healing of the skull base defect and diminished nasal crusting. ${ }^{26}$ Achieving adequate coverage of an inferior skull base defect such as the CVJ with a nasoseptal flap can sometimes prove difficult, especially in such a gravity-dependent area. Use of an inferiorly pedicled flap of the rhinopharynx (RPF) to help improve coverage of inferior skull base defects with viable tissues is being increasingly reported, without any evidence regarding its viability or clinical usefulness.

The viability of the RPF via robust vascularization is confirmed in the present study. On all routine postoperative examinations, the RPF appeared well healed without sign of necrosis, and on all immediate postoperative MR images, the RPF showed enhancement. Based on the nasoseptal flap literature, early flap enhancement is a good marker of viability. ${ }^{18,27,28}$ To help confirm flap viability intraoperatively, our group started using indocyanine green (ICG) given intravenously during reconstruction to visualize flap vascularization. Figure 3 shows intraoperative assessment of RPF viability using ICG. To help pinpoint and understand the vascular pedicle of the RPF, a cadaveric dissection was performed demonstrating the vascular pedicle of the RPF from the ascending pharyngeal artery (Figs. 4 and 5). From this dissection, it is clear that the vascular pedicle of the flap is in its inferior portion and comes close to midline, such that the inverted-U shape of the flap provides an optimal balance between the area exposed and pedicle preservation when compared with other opening techniques such as the midline incision and T-shaped opening.

The use of the RPF did not significantly alter the rate of postoperative CSF leakage. This result diverges from our initial hypothesis that the RPF would help diminish the
TABLE 3. Infectious agents involved with local infections

\begin{tabular}{|c|c|c|}
\hline & Nasopharynx* & Oropharynx* \\
\hline \multicolumn{3}{|l|}{ Control group } \\
\hline Staphylococcus aureus (4) & $x$ & $x$ \\
\hline Coagulase-negative staphylococci (3) & $x$ & $x$ \\
\hline Granulicatella sp. & & $x$ \\
\hline Capnocytophaga sp. & & $x$ \\
\hline Bacteroides sp. & & $x$ \\
\hline Candida sp. (2) & & $x$ \\
\hline Aspergillus sp. & & $\mathrm{x}$ \\
\hline Escherichia coli & & $x$ \\
\hline Enterococcus faecalis & & $\mathrm{x}$ \\
\hline Streptococcus anginosus (2) & & $\mathrm{x}$ \\
\hline Rothia sp. & & $x$ \\
\hline Streptococcus vestibularis & & $\mathrm{x}$ \\
\hline Veillonella sp. & & $\mathrm{x}$ \\
\hline$\alpha$-hemolytic streptococcus (3) & & $x$ \\
\hline \multicolumn{3}{|l|}{ RPF group } \\
\hline Coagulase-negative staphylococci & $x$ & $x$ \\
\hline Streptococcus mitis & $\mathrm{x}$ & $x$ \\
\hline Streptococcus constellatus & & $\mathrm{x}$ \\
\hline Corynebacterium sp. & $x$ & $x$ \\
\hline Peptostreptococcus sp. & $x$ & $x$ \\
\hline Aggregatibacter sp. & $x$ & \\
\hline
\end{tabular}

Numbers in parentheses represent the number of times the pathogen was found in cultures if more than once.

${ }^{*}$ An $\mathrm{x}$ indicates if the pathogen is preferentially found in the nasopharyngeal or oropharyngeal flora or both. $3,15,16,18,20,24,28$

rate of CSF leakage from the inferior portion of the construct and suggests that, for the purpose of preventing CSF leakage, the nasoseptal flap alone could be sufficient. During reconstruction, however, we have found the RPF to be helpful in securing or supporting the inferior edge of a fascia lata graft. Surprisingly, the RPF was inversely associated with nasoseptal flap necrosis and local infection, with a significant decrease of both in the RPF group. Of note, $71 \%(5 / 7)$ of cases with nasoseptal flap necrosis occurred concurrently with local infection, and 45\% (5/11) of local infections occurred in the setting of nasoseptal flap necrosis. The RPF could help prevent nasoseptal flap necrosis by providing additional vascular supply. It is also possible that the RPF could help diminish local infection by acting as a barrier between the oropharynx and nasopharynx during and after surgery, preventing contamination from oropharyngeal pathogens. The association between local infection and nasoseptal flap necrosis could go both ways. On one hand, local infection could lead to flap necrosis via inflammation and venous thrombosis. On the other hand, nasoseptal flap necrosis could be a nidus for local infection. Evidence that the RPF acts primarily via acting as a barrier for pathogens from the oropharynx comes from looking more closely at the bacterial pathogens isolated in the local infections of our cohort. Table 3 summarizes the bacterial pathogens by probable site of origin in the oropharynx, nasopharynx, or both. ${ }^{19-24,29}$ From this table, 

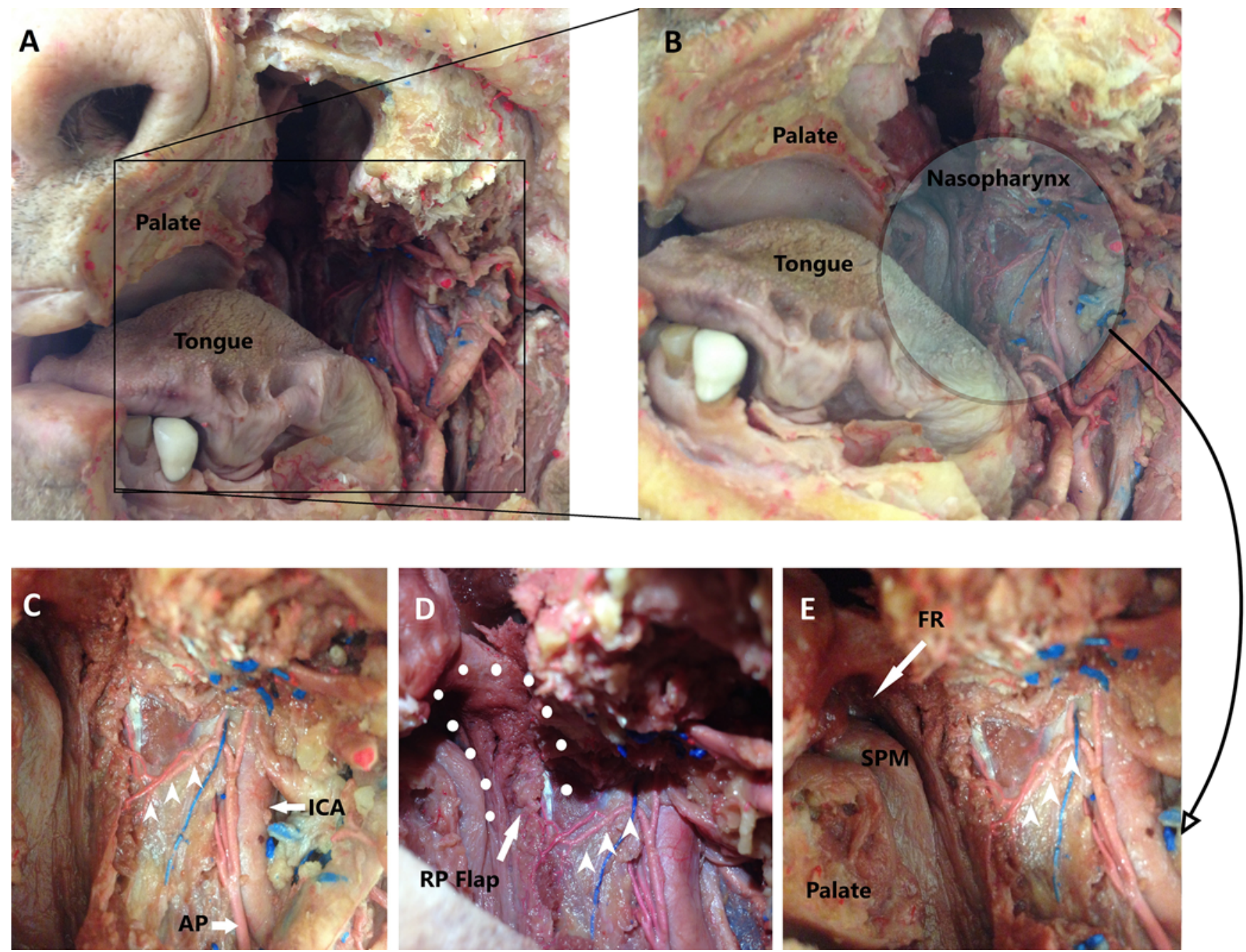

FIG. 4. Cadaveric dissection of the ascending pharyngeal artery showing the vascularization of the RPF. A: Macroscopic view of the specimen for orientation. For visualization of the flap pedicle, extensive neck dissection was performed combined with removal of the left jaw, left palate, and a portion of the left maxilla. B: Magnification of the image in panel A, showing the relationship of the zone of the flap and pedicle (circle) with the tongue and palate. C-E: Magnification of the zone encircled in panel B. In each of these panels the RPF vascular pedicle is shown with white arrowheads. Origin of the flap pedicle on the left from the ascending pharyngeal (AP) artery which runs superficial to the cervical internal carotid artery (ICA; panel C). Visualization of the RPF (white dots) with its pedicle (D). Relationship of the flap pedicle on the left with RP structures preserved on the right (E). FR = fossa of Rosenmuller; SPM = salpingopharyngeal muscle. Copyright Pierre-Olivier Champagne. Published with permission. Figure is available in color online only.

we see a clear predominance of oropharyngeal flora in the local infections of the control group, suggesting that in the RPF group, the RPF acted as a barrier to these pathogens. From our previous experience, ${ }^{18}$ the presence of fat grafts could lead to a higher rate of nasoseptal flap necrosis and infection. In the current study, use of a fat graft was not statistically associated with a higher rate of local infection $(25 \%$ infection rate with fat graft vs $11 \%$ without, $\mathrm{p}=$ $0.154)$ and/or nasoseptal flap necrosis (16\% flap necrosis rate with fat graft vs $7 \%$ without, $p=0.307)$. However, these rates do suggest a trend and the lack of statistical significance could be due to a lack of power.

One of the weaknesses of this study relies in its retrospective nature and the use of a historical control group. For example, with more experience over time, the harvest and handling of the nasoseptal flap could have improved, which could have contributed to the fewer cases of flap necrosis observed in the RPF group. However, the surgical team has significant experience, and the addition of the RPF was done as a refinement of an otherwise relatively stable reconstruction technique. Also, none of the baseline characteristics were statistically different between the groups. The same can be said for the various reconstruction adjuncts used between the groups, with the exception of tissue sealant. This definitely represents a historical trend within our group, representing the growing belief that dural sealant does not have a significant impact on CSF leakage rate. Also, regarding the historical nature of the control group, although the RPF group does represent more recent cases, there is a significant time overlap be- 


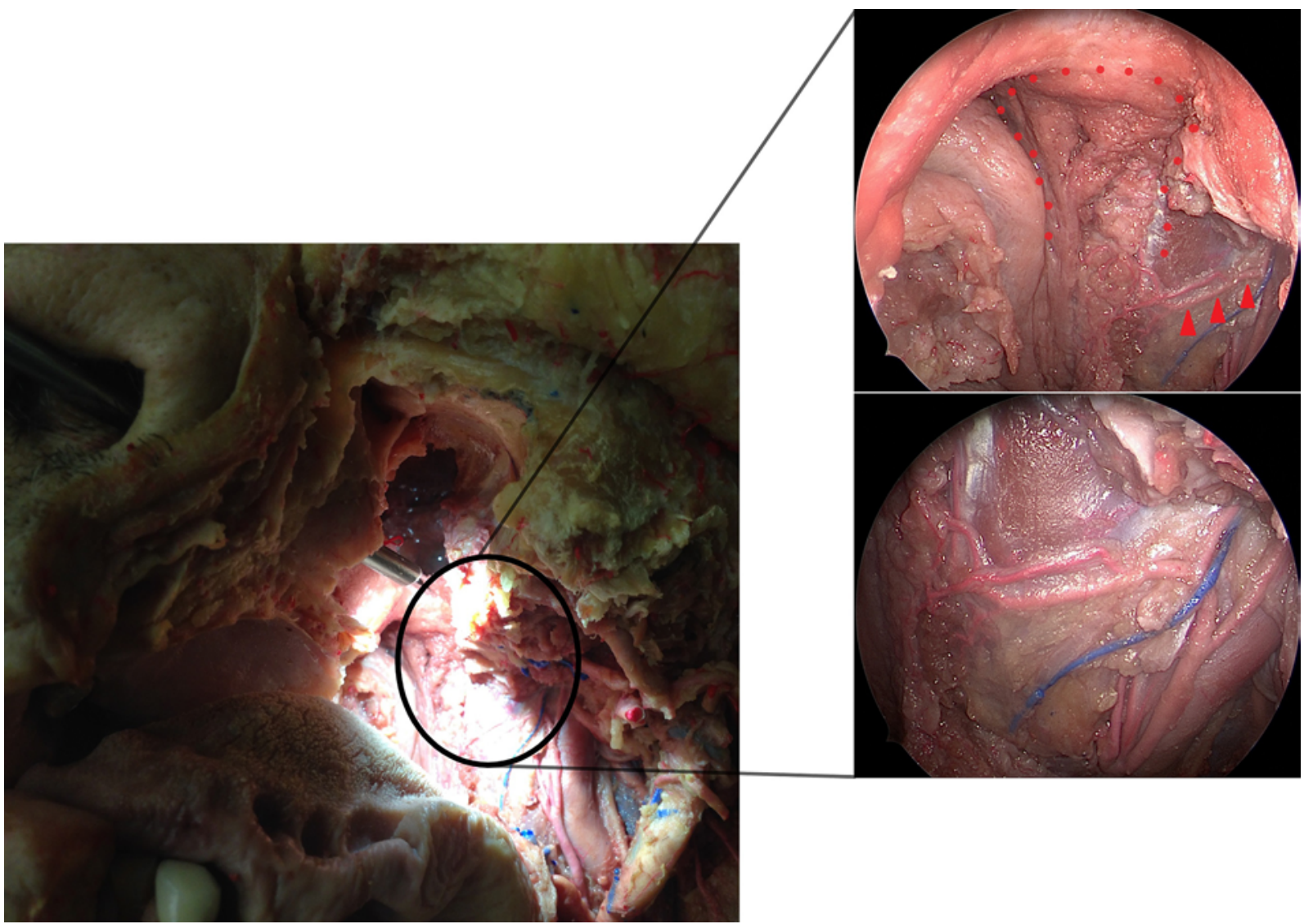

FIG. 5. Cadaveric dissection of the ascending pharyngeal artery showing the vascularization of the RPF viewed with an endoscope passed through the nose. The image on the left shows the passage of the endoscope. The upper image on the right shows the RPF (red dots) and its inferior vascular pedicle dissected on the left side (red arrowheads). The lower image on the right shows a focus on the vascular pedicle. Copyright Pierre-Olivier Champagne. Published with permission. Figure is available in color online only.

tween the groups, mainly in the 2 years during which more than $50 \%$ of the cases were performed (Fig. 2). This period represents the transition from not using the RPF to using it, with the decision to use the flap being mainly based on surgeon's preference rather than any established criteria of our team.

\section{Conclusions}

The RPF is a viable flap with a robust vascular pedicle. Its use in the reconstruction of $\mathrm{CVJ}$ and lower cranial base defects provides greater coverage of the surgical defect with vascularized tissue, leading to less local infection and nasoseptal flap necrosis while helping to keep the defect separate from the oropharynx. Although no effect on CSF leakage rate was found in the current study, its potential role in preventing CSF leakage in lower clival and CVJ surgery needs to be investigated.

\section{References}

1. Kassam AB, Snyderman C, Gardner P, et al. The expanded endonasal approach: a fully endoscopic transnasal approach and resection of the odontoid process: technical case report. Neurosurgery. 2005;57(1)(suppl):E213-E213.
2. Spina A, Gagliardi F, Abarca-Olivas J, et al. Endonasal endoscopic and transoral approaches to the craniovertebral junction and the clival region: a comparative anatomical study. World Neurosurg. 2019;132:e116-e123.

3. Kahilogullari G, Eroglu U, Yakar F, et al. Endoscopic endonasal approaches to craniovertebral junction pathologies: a single-center experience. Turk Neurosurg. 2019;29(4): 486-492.

4. Doglietto F, Belotti F, Qiu J, et al. Endonasal and transoral approaches to the craniovertebral junction: a quantitative anatomical study. Acta Neurochir Suppl. 2019;125:37-44.

5. Aldahak N, Richter B, Bemora JS, et al. The endoscopic endonasal approach to cranio-cervical junction: the complete panel. Pan Afr Med J. 2017;27:277.

6. Ponce-Gómez JA, Ortega-Porcayo LA, Soriano-Barón HE, et al. Evolution from microscopic transoral to endoscopic endonasal odontoidectomy. Neurosurg Focus. 2014;37(4):E15.

7. Yen Y-S, Chang P-Y, Huang W-C, et al. Endoscopic transnasal odontoidectomy without resection of nasal turbinates: clinical outcomes of 13 patients. J Neurosurg Spine. 2014; 21(6):929-937.

8. Tan SH, Ganesan D, Prepageran N, Waran V. A minimally invasive endoscopic transnasal approach to the craniovertebral junction in the paediatric population. Eur Arch Otorhinolaryngol. 2014;271(11):3101-3105.

9. Wu JC, Huang WC, Cheng H, et al. Endoscopic transnasal transclival odontoidectomy: a new approach to decompres- 
sion: technical case report. Neurosurgery. 2008;63(1)(suppl 1):ONSE92-ONSE94.

10. Choudhri O, Mindea SA, Feroze A, et al. Experience with intraoperative navigation and imaging during endoscopic transnasal spinal approaches to the foramen magnum and odontoid. Neurosurg Focus. 2014;36(3):E4.

11. Gempt J, Lehmberg J, Grams AE, et al. Endoscopic transnasal resection of the odontoid: case series and clinical course. Eur Spine J. 2011;20(4):661-666.

12. Iacoangeli M, Gladi M, Alvaro L, et al. Endoscopic endonasal odontoidectomy with anterior $\mathrm{C} 1$ arch preservation in elderly patients affected by rheumatoid arthritis. Spine $J$. 2013;13(5):542-548.

13. Gladi M, Iacoangeli M, Specchia N, et al. Endoscopic transnasal odontoid resection to decompress the bulbo-medullary junction: a reliable anterior minimally invasive technique without posterior fusion. Eur Spine J. 2012;21(1)(suppl 1): S55-S60.

14. Ogiwara T, Miyaoka Y, Nakamura T, et al. Endoscopic endonasal odontoidectomy in the hybrid operating room. World Neurosurg. 2019;131:137-140.

15. Mazzatenta D, Zoli M, Mascari C, et al. Endoscopic endonasal odontoidectomy: clinical series. Spine (Phila Pa 1976). 2014;39(10):846-853.

16. Yu Y, Wang X, Zhang X, et al. Endoscopic transnasal odontoidectomy to treat basilar invagination with congenital osseous malformations. Eur Spine J. 2013;22(5):1127-1136.

17. Lee A, Sommer D, Reddy K, et al. Endoscopic transnasal approach to the craniocervical junction. Skull Base. 2010;20(3): 199-205.

18. Chabot JD, Patel CR, Hughes MA, et al. Nasoseptal flap necrosis: a rare complication of endoscopic endonasal surgery. J Neurosurg. 2018;128(5):1463-1472.

19. van Uffelen R, van Saene HK, Fidler V, Löwenberg A. Oropharyngeal flora as a source of bacteria colonizing the lower airways in patients on artificial ventilation. Intensive Care Med. 1984;10(5):233-237.

20. Ylikoski J, Savolainen S, Jousimies-Somer H. Bacterial flora in the nasopharynx and nasal cavity of healthy young men. ORL J Otorhinolaryngol Relat Spec. 1989;51(1):50-55.

21. Odutola A, Antonio M, Owolabi O, et al. Comparison of the prevalence of common bacterial pathogens in the oropharynx and nasopharynx of gambian infants. PLoS One. 2013;8(9): e75558.

22. Lieberman D, Shleyfer E, Castel H, et al. Nasopharyngeal versus oropharyngeal sampling for isolation of potential respiratory pathogens in adults. J Clin Microbiol. 2006;44(2): 525-528.

23. Lemon KP, Klepac-Ceraj V, Schiffer HK, et al. Comparative analyses of the bacterial microbiota of the human nostril and oropharynx. MBio. 2010;1(3):e00129-10.

24. Ohara-Nemoto Y, Kishi K, Satho M, et al. Infective endocarditis caused by Granulicatella elegans originating in the oral cavity. J Clin Microbiol. 2005;43(3):1405-1407.
25. Zanation AM, Carrau RL, Snyderman CH, et al. Nasoseptal flap reconstruction of high flow intraoperative cerebral spinal fluid leaks during endoscopic skull base surgery. Am J Rhinol Allergy. 2009;23(5):518-521.

26. Battaglia P, Turri-Zanoni M, De Bernardi F, et al. Septal flip flap for anterior skull base reconstruction after endoscopic resection of sinonasal cancers: preliminary outcomes. Acta Otorhinolaryngol Ital. 2016;36(3):194-198.

27. Learned KO, Adappa ND, Lee JY, et al. MR imaging evolution of endoscopic cranial defect reconstructions using nasoseptal flaps and their distinction from neoplasm. AJNR Am J Neuroradiol. 2014;35(6):1182-1189.

28. Jyotirmay H, Saxena SK, Ramesh AS, et al. Assessing the viability of Hadad flap by postoperative contrast-enhanced magnetic resonance imaging. J Clin Diagn Res. 2017;11(6): MC01-MC03.

29. Deepa A, Nair BJ, Sivakumar T, Joseph AP. Uncommon opportunistic fungal infections of oral cavity: a review. J Oral Maxillofac Pathol. 2014;18(2):235-243.

\section{Disclosures}

Dr. Snyderman: direct stock ownership in and consultant for SPIWay LLC. Dr. Gardner: direct stock ownership in and consultant for SPIWay LLC, and royalties from and consultant for Peter Lazic US LLC.

\section{Author Contributions}

Conception and design: Gardner, Snyderman. Acquisition of data: Champagne. Analysis and interpretation of data: Champagne. Drafting the article: Champagne. Critically revising the article: Gardner, Zenonos, Wang. Reviewed submitted version of manuscript: all authors. Approved the final version of the manuscript on behalf of all authors: Gardner. Statistical analysis: Champagne. Administrative/technical/material support: Zenonos, Wang, Snyderman. Study supervision: Gardner, Snyderman.

\section{Supplemental Information \\ Videos}

Video 1. https://vimeo.com/462591462.

\section{Previous Presentations}

Portions of this paper were presented at the 30th Annual Meeting of the North American Skull Base Society, San Antonio, Texas, February 7-9, 2020.

\section{Correspondence}

Paul A. Gardner: University of Pittsburgh Medical Center, Pittsburgh,PA.gardpa@upmc.edu. 